\title{
Meconium stained liquor and fetal outcome: a hospital based follow up study
}

\author{
P. Kalpana*, A. Kavitha
}

Department of Obstetrics and Gynecology, Malla Reddy Medical College for Women, Suraram, Hyderabad, Telangana, India

Received: 08 April 2019

Accepted: 06 May 2019

\section{*Correspondence:}

Dr. P. Kalpana,

E-mail: kalpanapreddy67@gmail.com

Copyright: (c) the author(s), publisher and licensee Medip Academy. This is an open-access article distributed under the terms of the Creative Commons Attribution Non-Commercial License, which permits unrestricted non-commercial use, distribution, and reproduction in any medium, provided the original work is properly cited.

\section{ABSTRACT}

Background: Meconium staining of the amniotic fluid is a common problem occurring in 10-22\% of all deliveries. Meconium aspiration syndrome complicates approximately $1.5 \%$ of these deliveries with a reported mortality rate as high as $40 \%$. Objectives of the study were to determine whether meconium stained liquor during labour is associated with fetal distress and to check if there is any correlation in between the degree of meconium staining liquor and fetal outcome.

Methods: A clinical study of 200 cases of meconium stained amniotic fluid in cephalic presentation was undertaken among patients who were admitted in labour room were examined in detail and investigations were done. Fetal heart rate and its pattern were noted every fifteen min. Total APGAR score at one minute and five minute was noted down. Odds ratio with $95 \%$ confidence interval was calculated. Proportions were analyzed using chi square value.

Results: Majority of the study subjects belonged to the age group of 21-30 years. Majority i.e. 54.5\% were multigravida. Majority had toxemia in $24 \%$ of the cases. Fetal distress and the incidence of forceps delivery or LSCS was significantly more in those with thick meconium compared to those with thin meconium $(\mathrm{p}<0.05)$. But fetal asphyxia was not associated with type of stained meconium. It is seen that as the duration of the meconium staining increased, the proportion of babies with low APGAR score, perinatal mortality and morbidity increased.

Conclusions: Thick meconium stained amniotic fluid was associated with increased rate of interventions, neonatal morbidity and mortality compared to thin meconium stained meconium fluid.

Keywords: Meconium, Amniotic fluid, Delivery, Mortality, Morbidity, Outcome

\section{INTRODUCTION}

The appearance of meconium during any stage of labour has long been considered a clinical sign of fetal distress in other than breech presentation. The appearance of meconium as a sign of fetal distress has been questioned by many workers. ${ }^{1}$

The meconium staining of liquor is a direct sign representing the response of fetal gastro intestinal tract to hypoxic conditions. Any decrease in the oxygen concentration in the fetal blood induces hyper peristalsis of fetal gut and relaxation of anal sphincter. As a result the fetus passes meconium into the amniotic fluid. ${ }^{2}$

The passage of meconium represents normal physiological intra-amniotic defection by mature fetus just before instead of just after birth. The vital organs of fetus receive normal blood supply during hypoxia while the rest of the fetal non vital organs like skin and gut do not receive oxygenated blood as a result of vasoconstriction. The vaso constriction followed by hypoxia of fetal gut induces hyper peristalsis and sphincter relaxation and as a result fetus passes meconium. A 
mature fetus has the capacity of adaptive mechanism against hypoxia by peripheral vaso constriction in order to supply oxygenated blood to vital organs. ${ }^{3}$

Therefore that the fetus who have passed meconium during labour are in a state of compensated fetal distress. For short period $\mathrm{s}$ the state of compensation would persist. Perhaps a change in the fetal heart beats or a fall in the fetal scalp $\mathrm{pH}$ would suggest the end of the compensatory equilibrium and the intervention is indicated. ${ }^{4}$

Meconium staining of the amniotic fluid is a common problem occurring in $10-22 \%$ of all deliveries. Meconium aspiration syndrome complicates approximately $1.5 \%$ of these deliveries with a reported mortality rate as high as $40 \% .^{5}$

The aspiration of amniotic fluid stained with meconium can produce a spectrum of respiratory distress in the new born which varies from mild transient tachypnea to respiratory failure. ${ }^{6}$

Present study was carried out to determine whether meconium stained liquor during labour is associated with fetal distress and to check if there is any correlation in between the degree of meconium staining liquor and fetal outcome.

\section{METHODS}

A clinical study of 200 cases of meconium stained amniotic fluid in cephalic presentation was undertaken from October 1999 to September 2000 at Government Hospital, Gulbarga and Sangameshwar Hospital, Gulbarga attached to Mahadevappa Rampure Medical College, Gulbarga.

A careful clinical history was taken from all these cases particularly about age, parity, gravida, previous obstetric history, and obstetric complications.

\section{Inclusion criteria}

- Meconium stained amniotic fluid

- Cephalic presentation

- Patients who were having toxemia, premature rupture of membranes, prolonged labour, passing meconium were also included in this study

\section{Exclusion criteria}

- Presentation other than cephalic presentation

- Not willing to participate in this study

Color of amniotic fluid and type of meconium was noted at time of amniotomy or spontaneous rupture of membranes and at the time of delivery.
Patients who were admitted in labour room were examined in detail pertaining to age of the patient, parity, history of previous pregnancies, nature of delivery. General examination included pulse rate, temperature, blood pressure were recorded. Pitting edema was noted down. The general condition of the patient was noted down. Systemic examination was done. Cardiovascular system was examined for the presence or absence of murmurs is noted down. Lunges were carefully auscultated to rule out the clinical abnormalities.

The height of uterus, girth of the abdomen, the position and lie of the fetus were noted down. The fetal heart was auscultated carefully with stethoscope. Uterine action was also noted down carefully.

The position of the cervix, dilatation, the presence or absence of membranes, the level of the presenting part, type of pelvis were noted down carefully. If membranes were absent the type of liquor, whether it is meconium stained were noted down. If it was meconium, whether it was light green colored or dark green colored or thick meconium stained with tenacious meconium plugs was noted down.

Investigations like hemoglobin, total and differential count, blood grouping and typing and complete urine examination.

The patients who were having meconium stained amniotic fluid with or without heart rate variations were given $500 \mathrm{ml}$ to $1000 \mathrm{ml}$ of Ringer Lactate IV and oxygen inhalation to mother.

Fetal heart rate and its pattern was noted every fifteen min. bradycardia, tachycardia were noted down carefully. The rate of cervical dilatation, duration of labour was noted. If there were any associated complications like toxemia, essential hypertension, the specific treatment was given. The mode of delivery was dependent upon the fetal and maternal conditions. Depending on conditions, the delivery was either spontaneous or with stimulation, interventions like forceps, lower segment cesarean section were done.

Total APGAR score at one minute and five minute was noted down. The color of the baby, whether cyanosed or pink were noted down. The lunges were examined for aspiration syndrome and signs were noted down. The presence or absence of respiratory grunt was also noted. The weight and sex of the baby was also noted. If baby did not cry spontaneously at birth, resuscitative measures like oxygen inhalation or endotracheal intubation were carried out. Every baby born with meconium stained amniotic fluid was examined by pediatrician.

\section{Statistical analysis}

The data was entered in the Microsoft excel worksheet. Odds ratio with $95 \%$ confidence interval was calculated. Proportions were analyzed using chi square value. $\mathrm{P}$ 
value less than 0.05 was considered as statistically significant.

\section{RESULTS}

Table 1 shows distribution of study subjects as per baseline characteristics. Majority of the study subjects belonged to the age group of 21-30 years. 34\% of the study subjects were found in the age group of less than 20 years of age. There were only 15 cases above the age of 30 years. Majority i.e. $54.5 \%$ were multigravida. Majority had toxemia in $24 \%$ of the cases followed by premature rupture of the membrane in $13.5 \%$ of the cases. $7.5 \%$ were grandmultipara. $9 \%$ were having prolonged labour. There was only one case of elderly primipara and there were four cases with malpositions.

Table 1: Distribution of study subjects as per baseline characteristics.

\begin{tabular}{|llll|}
\hline Baseline characteristics & Number & $\%$ \\
\hline \multirow{3}{*}{$\begin{array}{l}\text { Age } \\
\text { (years })\end{array}$} & $<20$ & 68 & 34 \\
\cline { 2 - 4 } & $21-30$ & 117 & 58.5 \\
\cline { 2 - 4 } Parity & $>31$ & 15 & 7.5 \\
\hline \multirow{5}{*}{$\begin{array}{l}\text { Risk } \\
\text { factors }\end{array}$} & Primigravida & 91 & 45.5 \\
\cline { 2 - 4 } & Multigravida & 109 & 54.5 \\
\cline { 2 - 4 } & Toxemia & 48 & 24 \\
\cline { 2 - 4 } & Prolonged labour & 18 & 9 \\
\cline { 2 - 4 } & Premature rupture & 27 & 13.5 \\
\cline { 2 - 4 } & of membranes & 15 & 7.5 \\
\cline { 2 - 4 } & Erandmulti para & 2 & 1 \\
\cline { 2 - 4 } & Postadatism & 8 & 4 \\
\cline { 2 - 4 } & Malpositions & & 1.5 \\
\hline
\end{tabular}

Table 2 shows association between meconium staining with fetal distress and mode of delivery. The incidence of fetal distress in those with thick meconium was $54.5 \%$ compared to only $21.6 \%$ among those with thin meconium. This difference was found out to be statistically significant $(\mathrm{p}<0.05)$. The risk of fetal distress was 2.684 times more among those with thick meconium compared to those with thin meconium. The incidence of forceps delivery or LSCS was $67.9 \%$ among those with thick meconium compared to only $35.2 \%$ among those with thin meconium. This difference was found out to be statistically significant $(\mathrm{p}<0.05)$. The risk of forceps delivery or LSCS was 3.882 times more among those with thick meconium compared to those with thin meconium.

Table 3 shows APGAR score and stained meconium. Those with APGAR score of 0-3 at 1 min had incidence of thin meconium as $5.7 \%$ and the incidence of thick meconium was $7.1 \%$. Those with APGAR score of 4-6 at $1 \mathrm{~min}$ had incidence of thin meconium as $70.5 \%$ and the incidence of thick meconium was $71.4 \%$. Those with APGAR score of 7-10 at $1 \mathrm{~min}$ had incidence of thin meconium as $23.9 \%$ and the incidence of thick meconium was $3.6 \%$. Those with APGAR score of $0-3$ at $5 \mathrm{~min}$ had incidence of thin meconium as $0 \%$ and the incidence of thick meconium was $3.6 \%$. Those with APGAR score of 4-6 at $5 \mathrm{~min}$ had incidence of thin meconium as $2.3 \%$ and the incidence of thick meconium was $19.7 \%$. Those with APGAR score of 7-10 at 5 min had incidence of thin meconium as $97.7 \%$ and the incidence of thick meconium was $76.8 \%$.

Table 2: Association between meconium staining with fetal distress and mode of delivery.

\begin{tabular}{|c|c|c|c|c|}
\hline \multirow{3}{*}{ Risk factor } & \multicolumn{2}{|l|}{ Fetal distress } & \multirow{3}{*}{ OR $(95 \% \mathrm{CI})$} & \multirow{3}{*}{ P value } \\
\hline & Yes & No & & \\
\hline & $\mathrm{n}(\%)$ & $\mathrm{n}(\%)$ & & \\
\hline Thick meconium & $61(54.5)$ & $51(45.5)$ & \multirow{2}{*}{$\begin{array}{l}2.684(1.602- \\
4.645)\end{array}$} & \multirow{2}{*}{0.0002} \\
\hline Thin meconium & $19(21.6)$ & $69(78.4)$ & & \\
\hline \multirow{2}{*}{ Risk factor } & Mode of delivery & & & \\
\hline & Forceps or LSCS & Normal & & \\
\hline Thick meconium & $76(67.9)$ & $36(32.1)$ & \multirow{2}{*}{$\begin{array}{l}3.882(2.151- \\
7.005)\end{array}$} & \multirow{2}{*}{$<0.0001$} \\
\hline Thin meconium & $31(35.2)$ & $57(64.8)$ & & \\
\hline
\end{tabular}

Table 3: APGAR score and stained meconium.

\begin{tabular}{|lllllll|}
\hline APGAR score & & Thin meconium & $\%$ & Thick meconium & $\%$ \\
\hline \multirow{3}{*}{$1 \min$} & $0-3$ & 5 & 5.7 & 8 & 7.1 & 71.4 \\
\cline { 2 - 7 } & $4-6$ & 62 & 70.5 & 80 & 24 & 3.6 \\
\hline \multirow{3}{*}{$5 \min$} & $7-10$ & 21 & 23.9 & 4 & 24 & 19.7 \\
& $0-3$ & 0 & 2.3 & 22 & 76.8 \\
\hline
\end{tabular}


Table 4: Birth weight and meconium staining amniotic fluid.

\begin{tabular}{|lllll|}
\hline \multirow{2}{*}{ Birth weight $(\mathrm{kg})$} & Thin meconium & \multicolumn{3}{l|}{ Thick meconium } \\
\hline$<2.5$ & Number & $\%$ & Number & $\%$ \\
\hline $2.5-3.5$ & 15 & 17 & 16 & 14.3 \\
\hline$>3.5$ & 56 & 63.6 & 84 & 75 \\
\hline Total & 17 & 19.3 & 12 & 10.7 \\
\hline
\end{tabular}

Table 5: Association between meconium staining and fetal asphyxia.

\begin{tabular}{|lllll|}
\hline Risk factor & Fetal asphyxia & OR $(95 \%$ CI $)$ & P value \\
\cline { 1 - 3 } & Yes $(\%)$ & No $(\%)$ & \multirow{2}{*}{$1.618(0.8758-2.991)$} & 0.08239 \\
\hline Thick meconium & $41(38.4)$ & $69(61.6)$ & $66(75)$ & \\
\hline
\end{tabular}

Table 6: Association between meconium staining and fetal outcome.

\begin{tabular}{|c|c|c|c|c|}
\hline \multirow{2}{*}{ Risk factor } & \multicolumn{2}{|c|}{ Fetal outcome } & \multirow{2}{*}{ OR $(95 \% \mathrm{CI})$} & \multirow{2}{*}{ P value } \\
\hline & $\operatorname{Bad}(\%)$ & Good (\%) & & \\
\hline Thick meconium & $25(22.3)$ & $87(77.3)$ & \multirow{2}{*}{$3.325(1.364-8.105)$} & \multirow{2}{*}{0.0052} \\
\hline Thin meconium & $7(7.9)$ & $81(92.1)$ & & \\
\hline
\end{tabular}

Table 7: Effect of duration and density of meconium staining on fetal outcome.

\begin{tabular}{|c|c|c|c|c|c|c|c|}
\hline \multirow{2}{*}{$\begin{array}{l}\text { Duration of } \\
\text { meconium } \\
\text { staining }\end{array}$} & \multirow{2}{*}{$\begin{array}{l}\text { Density of } \\
\text { meconium }\end{array}$} & \multirow[b]{2}{*}{$\begin{array}{l}\text { Total } \\
\text { number }\end{array}$} & \multicolumn{2}{|c|}{ Fetal heart rate variation } & \multicolumn{3}{|c|}{ Number of babies with } \\
\hline & & & Number & $\%$ & $\begin{array}{l}\text { Low APGAR } \\
(\%)\end{array}$ & $\begin{array}{l}\text { Perinatal } \\
\text { mortality }(\%)\end{array}$ & $\begin{array}{l}\text { Morbidity } \\
(\%)\end{array}$ \\
\hline \multirow{2}{*}{1 hour } & Thin & 22 & 4 & 18.2 & 0 & 0 & 0 \\
\hline & Thick & 54 & 15 & 27.8 & 0 & 0 & $2(3.7)$ \\
\hline \multirow{2}{*}{$1-3$ hours } & Thin & 30 & 6 & 20 & 0 & 0 & $2(6.6)$ \\
\hline & Thick & 48 & 21 & 43.8 & $5(10.4)$ & $2(4.2)$ & $5(10.4)$ \\
\hline \multirow{2}{*}{ 3-6 hours } & Thin & 36 & 9 & 25 & $4(11.1)$ & $1(2.7)$ & $4(11.1)$ \\
\hline & Thick & 10 & 25 & 25 & $8(8)$ & $5(5)$ & $9(9)$ \\
\hline
\end{tabular}

Table 4 shows birth weight and meconium staining amniotic fluid. Those with birth weight less than $2.5 \mathrm{~kg}$, $17 \%$ of them had thin meconium and $14.3 \%$ of them had thick meconium. Those with birth weight between 2.5-3.5 $\mathrm{kg}, 63.6 \%$ of them had thin meconium and $75 \%$ of them had thick meconium. Those with birth weight more than $3.5 \mathrm{~kg}, 19.3 \%$ had thin meconium and $10.7 \%$ of them had thick meconium.

Table 5 shows association between meconium staining and feta asphyxia. The incidence of fetal asphyxia in those with thick meconium was $38.4 \%$ compared to $25 \%$ among those with thin meconium. This difference was not found out to be statistically significant $(p>0.05)$. $61.6 \%$ with thick meconium were found to have no fetal distress. $75 \%$ with thin meconium were found to have no fetal distress.

Table 6 shows association between meconium staining and fetal outcome. The incidence of bad fetal outcome was $22.3 \%$ among those with thick meconium compared to only $7.9 \%$ of the bad fetal outcome among those with thin meconium. This difference was found out to be statistically significant $(\mathrm{p}<0.05)$. Those with thick meconium had 3.325 times more risk of having bad fetal outcome compared to those with thin meconium.

Table 7 shows effect of duration and density of meconium staining on fetal outcome. It is seen that as the duration of the meconium staining increased, the proportion of babies with low APGAR score, perinatal mortality and morbidity increased. At one hour of meconium staining, there were 76 cases out of which 22 were having thin meconium and 54 were found to have thick meconium, but no one had low APGAR score and there was no perinatal mortality, there was no morbidity in thin meconium group and there were only two cases of morbidity in the thick meconium group. At 1-3 hours of duration of meconium staining, there were 78 cases out of which 30 were having thin meconium and 48 were found to have thick meconium. Out of these, there were no cases of low APGAR score and perinatal mortality in the thin meconium group but two cases had morbidity. In the thick meconium group, there were five cases of low APGAR score, two cases of perinatal mortality and five cases of morbidity. At 3-6 hours duration of meconium 
staining, there were more proportion of morbidity and mortality.

\section{DISCUSSION}

We found that there were $34 \%$ of the cases who belonged to the age group of less than 20 years of age, $58.5 \%$ of the cases who belonged to the age group of 21-30 years and $7.5 \%$ of the cases who belonged to the age group of more than 31 years. Similar findings were given by Nayak et al who found that there were $26.6 \%$ in $<20$ years, $66.9 \%$ in $21-30$ years and $6.7 \%$ in $>31$ years of age and also by Sandhu et al who reported that there were $8 \%$ in $<20$ years, $80 \%$ in $21-30$ years and $12 \%$ in $>31$ years of age. .,8 $^{-1}$

We noted that there were $45.5 \%$ of women who were primigravida and $54.5 \%$ who were multigravida. Similar findings of more proportion of multigravida were given by Nayak et al who reported that there were $38.3 \%$ primigravida women and $61.7 \%$ multigravida women in their study. Similarly Sandhu et al who reported that there were $38 \%$ women with primigravida and $62 \%$ of women with multigravida in their study.,8

We observed that there were $24 \%$ with toxemia, $9 \%$ with prolonged labour, $13.5 \%$ with premature rupture of membranes, and $7.5 \%$ with grand multipara. But Nayak et al observed in their study that there was less number of women with risk factors. ${ }^{7}$ There were only $10.3 \%$ women with toxemia, $6.9 \%$ with prolonged labour, $1.7 \%$ each with premature rupture of membranes and malpositions. There were no cases of grand multipara and elderly primipara in their study. But the findings of the study by Miller et al were similar to the findings of the present study as they had $23.6 \%$ of women with toxemia, but they had half number of women with premature rupture of membranes and grand multipara but more number of elderly primipara. ${ }^{7,9}$

We found that there were $21.6 \%$ of fetal distress cases who had thin meconium and $54.5 \%$ of fetal distress cases who had thick meconium. Similar findings were reported by Nayak et al who reported that there were $24.6 \%$ of cases of fetal distress who had thin meconium and $75.4 \%$ of fetal distress cases who had thick meconium. ${ }^{7}$

We noted that there were $64.8 \%$ of cases of normal delivery and rest some forceps or LSCS who had thin meconium and $32.1 \%$ of cases of normal delivery and rest some forceps or LSCS who had thick meconium. Thus from our study, there were more cases of abnormal delivery who had thick meconium. Similar findings were reported by Nayak et al who reported that there were $82.1 \%$ of cases of normal delivery and rest some forceps or LSCS who had thin meconium and $6.1 \%$ of cases of normal delivery and rest some forceps or LSCS who had thick meconium. ${ }^{7}$ Similarly Bhide et al who reported that there were $59.2 \%$ of cases of normal delivery and rest some forceps or LSCS who had thin meconium and
$49.3 \%$ of cases of normal delivery and rest some forceps or LSCS who had thick meconium. ${ }^{2}$

We observed that there were $17 \%$ cases of low birth weight in those with thin meconium and $14.3 \%$ cases of low birth weight in those with thick meconium. But Nayak AH et al who reported that there were $32.4 \%$ cases of low birth weight in those with thin meconium and $27.5 \%$ cases of low birth weight in those with thick meconium. $^{7}$

We found that there were $25 \%$ of cases of fetal asphyxia in those with thin meconium and $38.4 \%$ cases of low birth weight in those with thick meconium. Similar findings were reported by Nayak et al who reported that there were $20.1 \%$ of cases of fetal asphyxia in those with thin meconium and $39.2 \%$ cases of low birth weight in those with thick meconium. ${ }^{7}$

In our study $3 \%$ of cases of neonatal morbidity in those with thin meconium and $14.3 \%$ cases of low birth weight in those with thick meconium. Similar findings were reported by Nayak et al who reported that there were $5.6 \%$ of cases of neonatal morbidity in those with thin meconium and $8.2 \%$ cases of low birth weight in those with thick meconium. ${ }^{7}$

Rosario et al found that thick meconium stained liquor in labour was associated with fetal distress and this observation was in accordance with the findings of the present study. ${ }^{10}$

Coltart et al noted that the incidence of meconium aspiration syndrome was $0.2 \%$. The rate of mortality was found out to be 1 in 12 cases. No deaths were reported in so called sub-clinical meconium aspiration syndrome. ${ }^{11}$

Linder et al in their study had all infants underwent oropharyngeal suctioning with a De lee Catheter while the head was still on the perineum. ${ }^{12}$ In group I, suctioning of the trachea under direct vision was performed instantly at birth; in group II, this procedure was not done. There were no mortality among infants in the study, but morbidity, mainly pulmonary and laryngeal disorders occurred in 6 out of 308 group I infants and in more of the group II infants.

\section{CONCLUSION}

Meconium stained amniotic fluid alone is not an indicator of fetal distress. Especially the thin meconium stained amniotic fluid presence of thick meconium stained amniotic fluid in correlation with other factors like fetal heart rate alterations should be viewed seriously as it is potential danger sign for the baby. Thick meconium stained amniotic fluid was associated with increased rate of interventions, neonatal morbidity and mortality compared to thin meconium stained meconium fluid. 
Funding: No funding sources

Conflict of interest: None declared

Ethical approval: The study was approved by the Institutional Ethics Committee

\section{REFERENCES}

1. Abramovici H, Brandes JM, Fuchs K, Timor-Tritsch I. Meconium during delivery: a sign of compensated fetal distress. Am J Obstet Gynecol. $1974 ; 118(2): 251-5$

2. Bhide SS, Shedurnikar N, Aiyer S, Baxi SR. Neonatal outcome after meconium stained amniotic fluid. J Obstet Gynecol India. 1993;44:933-5.

3. Bacsik RD. Meconium aspiration syndrome. Pediatr Clin North Am. 1977;24(3):463-79.

4. Brown BL, Gleicher N. Intrauterine meconium aspiration. Obstet Gynecol. 1981;57(1):26-9.

5. Byrne DL, Gau G. In utero meconium aspiration: an unpreventable cause of neonatal death. Br J Obstet Gynecol. 1987;94:81.

6. Carson BS, Losey RW, Bowes WA Jr, Simmons MA. Combined obstetric and pediatric approach to prevent meconium aspiration syndrome. Am J Obstet Gynecol. 1976;126(6):712-5.

7. Nayak AH, Dalal AR. Meconium staining of amniotic fluid significance and fetal outcome. J Obstet Gynaecol India. 1991;41:480-3.
8. Sandhu SK, Singh J, Khura H, Kaur H. Critical evaluation of meconium staining of amniotic fluid and fetal outcome. J Obstet Gynaecol India. 1993;43:528-3

9. Miller FC, Sacks DA, Yeh SY, Paul RH, Schifrin BS, Martin CB Jr, et al. Significance of meconium during labor. Am J Obstet Gynecol. 1975;122(5):573-80.

10. Rosario MC, Sheshadri L. Meconium staining of amniotic fluid in low risk parturients. J Obst Gynae India. 1996;46:642-6.

11. Coltart TM, Byrne DL, Bates SA, Pearson JFFRCOG. Meconium Aspiration Syndrome: A 6Year Retrospective Study. Obstetric Anesthesia Digest 1990;9(4): Available at: https://journals.lww.com/obstetricanesthesia/abstract/ 1990/01000/meconium_aspiration_syndrome_a_6_ year.47.aspx. Accessed on 06 April 2019.

12. Linder N, Aranda JV, Tsur M, Matoth I, Yatsiv I, Mandelberg $\mathrm{H}$, et al. Need for endotracheal intubation and suction in meconium stained neonates. J Pediatr. 1988;112(4):613-5.

Cite this article as: Kalpana $\mathrm{P}$, Kavitha A. Meconium stained liquor and fetal outcome: a hospital based follow up study. Int J Reprod Contracept Obstet Gynecol 2019;8:2434-9. 